\title{
Effect of Short Period of Incubation during Egg Storage (Spides), Storage Period and Flock Age on Productivity of Post-Hatching Broiler Chickens \\ Mohamed Sowlem ${ }^{1}$, Ahmed Radwan, Gaafar El-Gendi ${ }^{2}$ and Osama El-Garhy ${ }^{3}$ \\ 1,2,3 Animal Production Dept., Fac. of Agric., Benha Univ., Egypt. \\ * Corresponding author: osama.alsayed@fagr.bu.edu.eg
}

\begin{abstract}
This study aimed to investigate the effect of applying the short period of incubation during egg storage (SPIDES) for the incubated eggs with relation to the periods of storage and the flock age on productive performance of post-hatching broiler chicks. A total number of 13500 eggs of broiler chicken breeders (Ross-308) obtained from El-Dakahlia Company of Poultry production. Eggs were randomly equally divided into two main groups (each of 6750 eggs), the $1^{\text {st }}$ group exposed to SPIDES at $100^{\circ} \mathrm{F}$ degree for 3.5 hours (egg shell temperature), and the $2^{\text {nd }}$ group didn't exposed to SPIDS and considered as control. Each main group divided into three sub-groups (each of 2250 eggs) according to the age of flock (29, 42 and 58 weeks, respectively). Each of sub-group divided into three sub-sub-groups (each of 750 eggs) according to the period of storage $(6,10$ and 14 days). The results obtained revealed that broiler chicks hatched from eggs of older flock showed higher averages of live body weight (LBW), body weight gain (BWG), performance index (PI), improvement in average feed conversion rate (FCR), eviscerated, giblets and total edible parts and it recorded lower average of mortality rate (MR) at the whole time of the experiment compared with those hatched from the prime and the young flocks. In addition, egg storage has significant effect on some productive traits of post-hatched broiler chickens. Moreover, it is clearly found that applying SPIDES showed significant improve in LBW, BWG, FCR and MR of broilers. However, it has no significant effect on averages PI and carcass weights of broiler chickens. Furthermore, the interaction among studied factors has showed significant effect on the most studied traits, it is clearly found that chicks hatched from old flock, storage for 10 days and exposing to SPIDES showed higher improvement in LBW, $\mathrm{BWG}, \mathrm{FC}$ and MR\%. While, chicks hatched from eggs of old flock, storage for 6 days and treated with SPIDES significantly increased averages of FCR and PI\%

From the obtained results of this study, it could be recommended to treating the incubated eggs with SPIDES to improve the productive performance of broilers. Thus, chicks hatched from old flock, storage for 10 days and exposing to SPIDES seemed to be adequate to achieve the favorable results for improve the productively of broiler chicks.
\end{abstract}

Keywords: egg warm up, flock age, egg storage, productivity, broiler chicken.

\section{Introduction}

The poultry industry has become an important economic activity in many countries. Poultry meat and its products have a vast consumer market and are making a significant contribution to the supply of good quality animal protein, vitamins and minerals (Mothershaw et al., 2009).

General Introduction

After oviposition, hatching eggs are first stored at the breeder farm, then transported to the hatchery and stored again before they are finally set in the incubator. The storage duration depends on the supply of hatching eggs, hatchery capacity, and market demand for day old chicks. Normally, commercial hatcheries set their eggs after 3 to 5 days of storage to minimize the negative effects of eggs storage on hatchability and chick quality. However, a hatchery may need to increase the storage duration in some situation. Especially in hatcheries that incubate eggs of grandparent stocks, storage duration beyond 7 days occur often (Tona et al., 2003), decrease hatchability (Yassin et al., 2008) decrease chick quality on the day hatch (Tona et al., 2004) decrease subsequent growth performance (Tona et al., 2004) and increase post hatch mortality (Yassin et al., 2009). Storage duration beyond 7 days has pronounced effect on hatchability (Yassin et al., 2008). On average, each extra day of storage of storage up to the seventh day of storage reduce hatchability by $0.2 \%$ whereas this percentage increase to $0.5 \%$ after the seventh day of storage (Yassin et al., 2008). There are evidence, however, that egg storage for more than 7 days deteriorated egg albumen and increased embryonic mortality and chicks (Van de ven 2004), incubation time; reduced hatchability; post hatch performance and chick quality (Peter and Dikmen, 2006; Ruiz and Lunman, 2002; Tona et al ., 2003)

A simple calculation shows that the negative effect of prolonged egg storage on hatchability has a substantial effect on the economic returns of a hatchery on a yearly basis. Although the negative effects of prolonged egg storage are well known, it is not totally understood why this extended storage has negative effects on hatchability, chick quality and it is associated with an increase of incubation duration (Tona et al ., 2004). After oviposition, $\mathrm{CO} 2$ and $\mathrm{H} 2 \mathrm{O}$ are lost from the egg, the albumen $\mathrm{PH}$ increase from about 7.6 to about 9.0 (Lapao et al ., 1999), yolk PH increase from about 6.0 to about 6.5 (shenstone,1968) 
, albumen height decreases (silversides and scott, 2001), and strength of the yolk membrane decreases as well (Fromm, 1966). Because the described changes both in the embryo and in the egg characteristics (micro environment of the embryo) occur during egg storage, it is difficult to distinguish which of these changes are involved in the negative effects of prolonged egg storage on hatchability and chick quality.

Due to variable market demands for one day old chick in the poultry industry and maximum hatchery capacity the total length of egg storage can vary between a few days and several weeks. Egg storage prior to incubation has been reported to have both detrimental as well as beneficial effects (Brake $\boldsymbol{e t}$ al., 1993).

After eggs are set on the day of oviposition, hatchability declines compared to eggs stored for 4 days (Asmundson and Macllraith, 1948). Benton and Brake (1996) hypothesized that this is caused by high albumen viscosity (albumen height) in fresh eggs, which impedes oxygen transport to the embryo. A storage duration beyond 7 days at standard storage condition (10-20 c and 50-80\% RH) cause a delay in hatch time (Tona et al., 2003) and decline in hatchability (Tona et al., 2004 ) and chick quality (Tona et al 2004 and Peter and Dikmen 2006). When eggs are set after prolonged egg storage $(>7$ days) embryo viability is reduced.

Many studies conducted to understand the negative effects of prolonged egg storage on embryo viability, tow important information need to identify, which factors affect embryo viability during storage and early incubation and how can the reduction in embryo viability be prevented. Many investigators try to facilitate this negative effect due to egg storage, during egg storage, embryo viability declines, likely due to an increase in cell death (Bloom et al., 1998). If the fertile eggs are stored for more a few days, the embryos start die. After (10-12) days of storage more than half of cells percentage at oviposition will have died (Bakst et al., 2012). After (10-12) days of storage more than half of cells percentage at oviposition will have died (Bakst et al., 2012). Commercial broiler hatcheries strive to set their eggs after 3 to 5 days of storage to minimize negative effects of egg storage on hatchability and chick quality (Reijrink et al ., 2008, 2010a)

Many trials had conducted to decrease the negative effects of prolonged egg storage, several authors increased the stage of embryonic development by using pre-storage incubation (Fasenko et al., 2001a,b). Pre-storage incubation (Fasenko et al 2001a,b) or short period of incubation during storage (SPIDES); Nicholson et al 2011; Diamond et al .2013) demonstrated that to reduce negative effects of prolonged egg storage. The temperature profile used to warm eggs (warming profile; WP) from storage temperature to incubation temperature affects early mortality and hatchability in long-stored eggs as well (Reijrink et al., 2010a). The most promised one is to warm eggs prior to or during storage (Fasenko, 1997; Anonymous, 2000). Warming of eggs before storage was reported to increase hatchability and reduced embryonic mortality (Fasenko et al, 2001 a,b). Petek and Dikmen (2004) absorbed that long period storage decreased apparent fertility. However, Elibol $\boldsymbol{e t}$ al., (2002) and Gharib (2013) found that there are no significant effect in the apparent fertility when they storage eggs for four, seven, ten and

Fourteen days at $18 \mathrm{c}$ and $75 \% \mathrm{RH}$. However, Petek and Dikmen (2006) demonstrated that warming broiler eggs for 4 and $8 \mathrm{~h}$ at $38^{\circ}$ significantly decreased fertility compared to control eggs. Yasin $\boldsymbol{e t}$ al., (2008) reported that preheating of eggs influenced the metabolic activity of chick embryo. In addition, Effect of storage duration on hatchability is influenced by breeder age (Yasin et al., 2008).

From the previous information, the present study is carried out to investigate and emphasis that the short period of incubation during storage (SPIDES) may has a positive or negative effect on embryonic development, chick's quality, hatchability and posthatching performance with relation to both egg storage period and the age of breeder which produced that eggs .

This study aimed of was to investigate and emphasis the effect of applying the short period of incubation during egg storage (SPIDES) for the incubated eggs with relation to the periods of storage and the flock age on hatchability, chicks quality and post-hatching productive performance of broiler chicken.

\section{Material and methods:}

This experiment was carried out at the Association of Al tanmia for hatching and poultry production at El-Khanka, El-Qalyubia Governorate, Egypt and Poultry Research Farm belonging to the department of Animal production, Faculty of Agriculture, Benha University during the period from the $1^{\text {th }}$ September to $9^{\text {th }}$ of November 2019 .

A total number of 13500 eggs of Ross-308 broiler chicken obtained from El-Dakahlia Company of Poultry production. Eggs were randomly equally divided into two main groups (each of 6750 eggs), the $1^{\text {st }}$ group exposed to SPIDES at $100^{\circ} \mathrm{F}$ degree for four hours (egg shell temperature), and the $2^{\text {nd }}$ group nonexposed to SPIDS considered as control. Each main group divided into three sub-groups (each of $2250 \mathrm{eggs})$ according to the age of flock (29, 42 and 58 weeks, respectively). Each of sub-group divided into three sub-sub-groups (each of 750 eggs) according to the period of storage (6,10 and 14 days). The experimental design and the experimental groups were summarized in the following table (1) 


\begin{tabular}{ccc}
\hline $\begin{array}{c}\text { Treatment } \\
\text { (each of 6750 eggs) }\end{array}$ & $\begin{array}{c}\text { Age of flock } \\
\text { (each of 2250eggs) }\end{array}$ & $\begin{array}{c}\text { Period of Storage } \\
\text { (each of 750eggs) }\end{array}$ \\
\hline $\begin{array}{c}\text { Young flock } \\
\text { Exposed to SPIDS }\end{array}$ & (29 weeks) & 10 days \\
Prime flock & 14 days \\
storage) & $(42$ weeks) & 6 days \\
& & 10 days \\
& Old flock & 14 days \\
& $(58$ weeks) & 6 days \\
& & 10 days \\
& Young flock & 14 days \\
& $(29$ weeks) & 6 days \\
Untreated eggs & & 10 days \\
(control) & Prime flock & 14 days \\
& $(42$ weeks) & 6 days \\
& & 10 days \\
& Old flock & 14 days \\
& $(58$ weeks) & 10 days \\
& & 14 days \\
\hline
\end{tabular}

All eggs of experimental groups were kept in storage cooling room before incubation at $15^{\circ} \mathrm{C}$, relative humidity $75 \%$ and turning three times per day with $90^{\circ}$ angle. Eggs of experimental groups treated with worm up for short period of incubation (SPIDES) were applied by removing to the incubator at $100^{\circ} \mathrm{F}$ (egg shell temperature) and relative humidity $53 \%$ for 3.5 hours. Eggs were then turning back to the storage cooling room after cooled down gradually in the hall for 3 hours at $24^{\circ} \mathrm{C}$ egg shell temperature (SPIDES) was applied for treated groups each 4 days of storage period.

After storage period each experimental group, eggs were removed to the room of incubators for 8 hours at $25^{\circ} \mathrm{C}$ (pre-incubation preparation). Eggs were then put in the incubator machine with applying of the traditional incubation conditions program according to the manufactured company (Pas Reform ${ }^{\circledR}$ Smart).Eggs were turned automatically through an angle of $90^{\circ}$ every hour until the $18^{\text {th }}$ day of the incubation period. Ventilation channels were opened automatically and measured as relative value of the air inlet opening area of the ventilation channels as referred in the previous table.

After hatching of chicks, a total number of 450 chicks ( 25 chicks from each experimental group) were randomly chosen, placed to the rearing farm to perform the post-hatching experiment. Chicks were weighed at hatch; wing banded, vaccinated against Newcastle (New Castle disease virus) and Gumboro (infectious bursal virus diseases), chicks kept under similar standard hygienic and environmental conditions. Brooding house provided with plastic floor and gas heaters were used for brooding chicks. Chicks were fed ad-libitum on commercial prestarting, starting, growing and finishing ration with composition and nutritive value According to NRC, 1994 showed in table (2). 
Table 2. The composition and calculated analyses of experimental starter and grower diets:

\begin{tabular}{lll}
\hline Ingredients, \% & Starter Diet & Grower Diet \\
\hline & & \\
Yellow corn & 59.90 & 61.00 \\
Soybean meal (48\%) & 28.10 & 00.00 \\
Soybean meal (44\%) & 00.00 & 24.90 \\
Corn gluten meal (60\%) & 7.00 & 6.60 \\
Di-Calcium phosphate & 2.00 & 2.30 \\
Limestone & 1.30 & 1.20 \\
Salt & 0.50 & 0.40 \\
Oil & 0.20 & 2.3 \\
Premix* & 0.40 & 0.30 \\
Methionine & 0.19 & 0.13 \\
Lysine & 0.38 & 0.37 \\
Anti-Coccidian & 0.03 & 0.30 \\
Anti-Toxin & 0.00 & 0.20 \\
Total & 100.00 & 100.00 \\
ME, Kcal/Kg & 2984 & 3097 \\
Crude Protein $(\%)$ & 22.8 & 20.1 \\
Calcium $(\%)$ & 1.09 & 1.08 \\
Phosphorus $(\%)$ & 0.57 & 0.63 \\
Crude Fiber $(\%)$ & 1.19 & 1.22 \\
Methionine $(\%)$ & 0.63 & 0.54 \\
Lysine $(\%)$ & 1.35 & 1.24 \\
\hline
\end{tabular}

"Each kg of premix provided: Vit. A, $12000 \mathrm{IU}$, vit. E (dl-a-tocopheryl acetate) $20 \mathrm{mg}$, menadione $2.3 \mathrm{mg}$, Vit. D3, $2200 \mathrm{ICU}$, riboflavin $5.5 \mathrm{mg}$, calcium pantothenate $12 \mathrm{mg}$, nicotinic acid $50 \mathrm{mg}$, Choline $250 \mathrm{mg}$, vit. B12 $10 \mathrm{mg}$, vit. B6 $3 \mathrm{mg}$, thiamine $3 \mathrm{mg}$, folic acid $1 \mathrm{mg}$, d-biotin $0.05 \mathrm{mg}$, Mn $80 \mathrm{mg}$, Zn $60 \mathrm{mg}$, Fe 35 $\mathrm{mg}, \mathrm{Cu} 8 \mathrm{mg}$, Selenium $0.1 \mathrm{mg}$. * diets were provided as recommended by (NRC, 1994).

\section{Parameter estimated and data collection}

Chicks were individually weighed to the nearest $(\mathrm{g})$ at hatch, and then at the $3^{\text {th }}$ and $6^{\text {th }}$ week of bird's age. Weight gain and rate of growth were individually calculated according to the following formula suggested by Broody (1949). Weight gain = W2-W1, Where; W1 and W2 are individual body weight at the two successive periods.

Feed consumed by all chicks was weekly recorded for each treatment. It was then averaged and expressed in gram per chicks at the periods from (0-3), (3-6) and (0-6) weeks of chicks' age. Feed conversion (F.C.) was calculated according to the following formula: F.C = Feed consumption (g)/ Weight gain $(\mathrm{g})$.

Mortality rate of grower chicks was calculated by subtracting the number of the live birds at the end of the experiment from the initial total number of birds according to the following formula, Mortality rate (\%) $[(\mathrm{I}-\mathrm{E}) / \mathrm{I} * 100]$ whereas; I: initial number of birds and E: number of live birds at the end of the experimental period

Performance index (PI) was estimated of different experimental group at the whole periods of the experiment according to the equation suggested by North, (1981): Performance index $(\mathrm{PI})=($ Live body weight $(\mathrm{kg}) /$ Feed conversion $\times 100$.

Carcass characteristics for random sample of 4 birds from each experimental group were performed at the end of the experimental period (5 weeks). Birds chosen were deprived from feed for 16 hours, individually weighed to the nearest $g$ and killed by cutting the throat and the jugular veins with a sharp knife near the first neck vertebra. Birds were reweighed individually after complete bleeding. Shank and head were separated, the birds were then eviscerated and intestine, gizzard, lungs, spleen, liver, heart and all internal organs were removed. The carcass and giblets (empty gizzard, liver and heart) were separately weighed. The proportional weights to live weight of giblets, carcass and total edible parts were calculated as following: Giblets weight $(\%)=$ $[(\mathrm{GW} / \mathrm{LW}) * 100$, Edible parts $(\%)=[(\mathrm{EW}+\mathrm{GW}) /$ LW]*100, whereas; LW = live weight, $\mathrm{GW}=$ giblets weight and $\mathrm{EW}=$ eviscerated weight

\section{Statistical analysis:}

Analysis of variance was calculated using SAS procedure guide (SAS 2004) using the following linear model:

$\mathbf{X}_{\mathrm{ijkl}}=\mu+\mathbf{T}_{\mathrm{i}}+\mathbf{G}_{\mathbf{j}}+\mathbf{P}_{\mathrm{k}}+\mathbf{T G}_{\mathrm{ij}}+\mathbf{T P}_{\mathrm{ik}}+\mathbf{G P}_{\mathbf{j k}}$ + TGP $_{\mathrm{ijk}}+\mathrm{e}_{\mathrm{ijk} \mathrm{l}}$

Whereas;

$\mathrm{X}_{\mathrm{ijkl}}=$ the $\mathrm{i}^{\text {th }}$ observation, $\mu=$ overall mean, $\mathrm{T}_{\mathrm{i}}=$ effect of the $i^{\text {th }}$ treatment (SPIDS), $G_{j}=$ effect of the $j^{\text {th }}$ flock age, $\mathrm{P}_{\mathrm{k}}=$ effect of the $\mathrm{k}^{\text {th }}$ storage period, $\mathrm{TG}_{\mathrm{ij}}=$ the interaction between $i^{\text {th }}$ treatment (SPIDS) and $j^{\text {th }}$ flock age, $\mathrm{TP}_{\mathrm{ik}}=$ the interaction between $\mathrm{i}^{\text {th }}$ treatment (SPIDS) and $\mathrm{k}^{\text {th }}$ storage period $\mathrm{GP}_{\mathrm{Jk}}=$ the interaction between $\mathrm{j}^{\text {th }}$ flock age and $\mathrm{k}^{\text {th }}$ storage period, $\mathrm{TGP}_{\mathrm{ijk}}=$ the interaction among $\mathrm{i}^{\text {th }}$ treatment (SPIDS) and $\mathrm{j}^{\text {th }}$ flock age as well as $\mathrm{k}^{\text {th }}$ storage period, $\mathrm{e}_{\mathrm{ijkl}}=$ the experimental error. 


\section{Results and Discussion}

\section{Live body weight (LBW)}

Data presented in table (3) revealed that broiler chicks hatched from older flock showed higher average live body weight (LBW) at hatch, the $3^{\text {rd }}$ and $5^{\text {th }}$ weeks of age compared with those hatched from the prime and the young flocks. This result seems quite logic sense the ode flock laid higher eggs weights compared to both the prime and the young flocks. Concerning to the effect of storage period of incubated eggs on LBW of hatched chicks, it is clearly observed that chicks hatched from eggs stored for 10 days showed higher LBW at hatch, $3^{\text {rd }}$ and $5^{\text {th }}$ weeks of age compared with those hatched from eggs stored for 6 or 14 days. These results may attribute to the negative effects of prolonged egg storage which decrease hatchability (Yassin et al., 2008), chick quality on the day hatch and decrease subsequent growth performance as well (Tona et al., 2004). While, it is quite clear that short period of incubation during storage (SPIDES) treating of incubated eggs had showed significant increase of LBW at hatch, $3^{\text {rd }}$ and $5^{\text {th }}$ weeks of age compared with un-treated one. This a good results attributed to warm eggs prior to or during storage (Fasenko, 1997; Anonymous, 2000 and Fasenko et al, 2001 a,b) which lead to improve growth performance in subsequently. The interaction effect among studied factors had significant effect on LBW, it is clearly evidence that hatched chicks from eggs of old flock, stored for 10 days and exposed to SPIDES showed highest average LBW ( 2966.7g) at the end of the experiment, followed by those hatched from eggs of prime flock, stored for 10 days and treated with SPIDES mounted (2816.66g).

Table 3. Least - square means and standard error $(\overline{\mathrm{X}} \pm \mathrm{S}$. $\mathrm{E})$ for live body weight $(\mathrm{g})$ of different experimental groups as affected by studied factors

\begin{tabular}{|c|c|c|c|c|}
\hline \multicolumn{2}{|c|}{ Items } & \multicolumn{3}{|c|}{ Live body weight (g) at } \\
\hline & & Hatch & 3 WKS & $5 \mathrm{WKS}$ \\
\hline \multirow{3}{*}{ FA } & Young & $35.71 \pm 0.02^{c}$ & $1033.36 \pm 11.16^{\mathrm{c}}$ & $2516.66 \pm 18.60^{c}$ \\
\hline & Prime & $41.28 \pm 0.02^{b}$ & $1139.70 \pm 11.03^{b}$ & $2674.99 \pm 18.12^{\mathrm{a}}$ \\
\hline & Old & $47.21 \pm 0.02^{\mathrm{a}}$ & $1184.72 \pm 11.57^{\mathrm{a}}$ & $2780.55 \pm 19.08^{b}$ \\
\hline \multirow{3}{*}{ ST } & 6 days & $41.25 \pm 0.02^{c}$ & $1115.96 \pm 11.32^{\mathrm{ab}}$ & $2669.44 \pm 18.79$ \\
\hline & 10 days & $41.54 \pm 0.02^{\mathrm{a}}$ & $1139.68 \pm 11.25^{\mathrm{a}}$ & $2655.55 \pm 18.54$ \\
\hline & 14 days & $41.41 \pm 0.02^{b}$ & $1102.14 \pm 11.21^{b}$ & $2647.22 \pm 18.48$ \\
\hline \multirow[t]{10}{*}{ SP } & Control & $41.32 \pm 0.01^{\mathrm{a}}$ & $1095.74 \pm 9.19^{\mathrm{b}}$ & $2609.25 \pm 15.22^{b}$ \\
\hline & SPIDES & $41.84 \pm 0.01^{\mathrm{b}}$ & $1142.78 \pm 9.19^{a}$ & $2705.55 \pm 15.16^{a}$ \\
\hline & $\mathrm{P} \times 6 \mathrm{~d} \times \mathrm{C}$ & $41.31 \pm 0.05^{\mathrm{f}}$ & $1132.88 \pm 26.85^{\mathrm{acdf}}$ & $2633.33 \pm 44.84^{\mathrm{efh}}$ \\
\hline & $\mathrm{P} \times 6 \mathrm{~d} \times \mathrm{SP}$ & $41.60 \pm 0.05^{\mathrm{e}}$ & $1211.81 \pm 28.62^{\mathrm{a}}$ & $2783.33 \pm 47.94^{\mathrm{bcd}}$ \\
\hline & $P \times 10 d \times C$ & $41.13 \pm 0.05^{\mathrm{g}}$ & $1084.86 \pm 27.99^{\mathrm{cdfg}}$ & $2650.00 \pm 46.84^{\mathrm{defh}}$ \\
\hline & $P \times 10 d \times S P$ & $41.33 \pm 0.05^{\mathrm{f}}$ & $1157.20 \pm 26.85^{\mathrm{ac}}$ & $2816.66 \pm 44.84^{\mathrm{bc}}$ \\
\hline & $\mathrm{P} \times 14 \mathrm{~d} \times \mathrm{C}$ & $41.08 \pm 0.05^{\mathrm{g}}$ & $1098.20 \pm 26.85^{\mathrm{cdfg}}$ & $2683.33 \pm 43.94^{\text {cdef }}$ \\
\hline & $\mathrm{P} \times 14 \mathrm{~d} \times \mathrm{SP}$ & $41.22 \pm 0.05^{\mathrm{fg}}$ & $1153.28 \pm 26.85^{\mathrm{acd}}$ & $2483.33 \pm 44.84^{\mathrm{ijk}}$ \\
\hline & $\mathrm{O} \times 6 \mathrm{~d} \times \mathrm{C}$ & $47.31 \pm 0.05^{\mathrm{b}}$ & $1176.04 \pm 26.85^{\mathrm{a}}$ & $2700.00 \pm 44.84^{\text {cdef }}$ \\
\hline & $\mathrm{O} \times 6 \mathrm{~d} \times \mathrm{SP}$ & $47.48 \pm 0.05^{\mathrm{a}}$ & $1198.12 \pm 27.40^{\mathrm{a}}$ & $2866.66 \pm 44.84^{\mathrm{ab}}$ \\
\hline \multirow{10}{*}{$\mathbf{F A} \times \mathbf{S T} \times \mathbf{S P}$} & $\mathrm{O} \times 10 \mathrm{~d} \times \mathrm{C}$ & $47.16 \pm 0.05^{\mathrm{bc}}$ & $1160.20 \pm 27.40^{\mathrm{ac}}$ & $2700.00 \pm 44.84^{\text {cdef }}$ \\
\hline & $\mathrm{O} \times 10 \mathrm{~d} \times \mathrm{SP}$ & $47.29 \pm 0.05^{\mathrm{bc}}$ & $1212.40 \pm 26.85^{\mathrm{a}}$ & $2700.00 \pm 43.94^{\text {cdef }}$ \\
\hline & $\mathrm{O} \times 10 \mathrm{~d} \times \mathrm{C}$ & $46.92 \pm 0.05^{\mathrm{d}}$ & $1023.47 \pm 26.85^{\mathrm{acd}}$ & $2750.00 \pm 43.94^{\text {bcde }}$ \\
\hline & $\mathrm{O} \times 10 \mathrm{~d} \times \mathrm{SP}$ & $47.13 \pm 0.05^{\mathrm{c}}$ & $1219.88 \pm 26.85^{\mathrm{a}}$ & $2966.66 \pm 43.94^{\mathrm{a}}$ \\
\hline & $\mathrm{Y} \times 6 \mathrm{~d} \times \mathrm{C}$ & $35.80 \pm 0.05^{\mathrm{h}}$ & $1051.95 \pm 27.99^{\text {fgi }}$ & $2466.66 \pm 46.84^{\mathrm{jk}}$ \\
\hline & $\mathrm{Y} \times 6 \mathrm{~d} \times \mathrm{SP}$ & $35.78 \pm 0.05^{\mathrm{h}}$ & $1067.27 \pm 28.62^{\text {dgif }}$ & $2616.66 \pm 46.84^{\text {fhij }}$ \\
\hline & $\mathrm{Y} \times 10 \mathrm{~d} \times \mathrm{C}$ & $35.73 \pm 0.05^{\mathrm{h}}$ & $992.38 \pm 29.30^{\mathrm{i}}$ & $2516.66 \pm 47.94^{\mathrm{hijk}}$ \\
\hline & $\mathrm{Y} \times 10 \mathrm{~d} \times \mathrm{SP}$ & $35.82 \pm 0.05^{\mathrm{h}}$ & $1005.80 \pm 26.85^{\mathrm{i}}$ & $2550.00 \pm 43.94^{\mathrm{hij}}$ \\
\hline & $\mathrm{Y} \times 14 \mathrm{~d} \times \mathrm{C}$ & $35.49 \pm 0.05^{\mathrm{i}}$ & $1141.68 \pm 27.99^{\mathrm{gi}}$ & $2383.33 \pm 46.84^{\mathrm{k}}$ \\
\hline & $\mathrm{Y} \times 14 \mathrm{~d} \times \mathrm{SP}$ & $35.67 \pm 0.05^{\mathrm{h}}$ & $1059.28 \pm 29.30 \mathrm{f}^{\mathrm{gi}}$ & $2616.66 \pm 47.94^{\text {efhi }}$ \\
\hline
\end{tabular}

Mean having similar letters in each column within each effect are not significantly different.

Where; FA= Flock age, $\mathrm{ST}=$ storage period and $\mathrm{SP}=$ short period of incubation during storage (SPIDES)

\section{Body weight gain (BWG)}

The obtained results showed in table (4) revealed that broiler chicks hatched from eggs of older flock showed higher average BWG at the different periods of the experiment (0-3, 3-5 and 0-5 weeks of age) compared to those hatched from the prime and the young flocks. This result goes in same trend with live body weight sense it has calculated a different between average body at the two successive periods and it has also affected by the weight of laid egg whereas the old flocks produce higher egg weight compared to both the prime and the young flocks. Although there is no significant different in BWG of broiler hatched chicks due to the effect of storage period, it is clearly observed that chicks hatched from eggs stored for 10 days showed higher 
BWG mounted ( 2733.33at the whole period of the experiment (at hatch to 5 weeks of age) compared with those hatched from eggs stored for 6 or 14 days. These results may attribute to the negative effects of prolonged egg storage more than 10 days which decrease hatchability (Yassin et al., 2008), chick quality on the day hatch and decrease subsequent growth performance as well (Tona et al., 2004). Concerning the effect of short period of incubation during storage (SPIDES) treating of incubated eggs on BWG of the grower hatched chicks, it is obvious that significant increase in BWG of broiler chicks hatched from eggs treated with SPIDES during the different time of estimations compared with those hatched from un-treated one. This result attributed to warm eggs during storage (Fasenko, 1997; Anonymous, 2000 and Fasenko et al, 2001 a,b) which lead to improve growth in subsequently. The interaction effect among the studied factors showed significant differences in BWG, it is clearly evidence that chicks hatched from eggs of old flock, stored for 10 days and exposed to SPIDES showed highest average BWG (2919.53g) at the whole period of the experiment $(0-5 \mathrm{wks})$, followed by those hatched from eggs of prime flock, stored for 10 days and treated with SPIDES (2775.34g).

Table 4. least - square means and standard error $(\bar{X} \pm S . E)$ for body weight gain $(\mathrm{g})$ of different experimental groups as affected by studied factors

\begin{tabular}{|c|c|c|c|c|}
\hline \multicolumn{2}{|c|}{ Items } & \multicolumn{3}{|c|}{ Body weight gain (g) during } \\
\hline & & 0 - 3 WKS & $3-5 \mathrm{WKS}$ & 0 - 5 WKS \\
\hline \multirow{4}{*}{ FA } & Young & $997.65 \pm 11.57^{\mathrm{c}}$ & $1483.64 \pm 22.5^{\mathrm{b}}$ & $2480.95 \pm 19.08^{c}$ \\
\hline & Prime & $1098.43 \pm 11.16^{\mathrm{b}}$ & $1534.09 \pm 21.44^{\mathrm{b}}$ & $2633.72 \pm 18.60^{\mathrm{b}}$ \\
\hline & Old & $1137.50 \pm 11.03^{\mathrm{a}}$ & $1596.90 \pm 22.5^{\mathrm{a}}$ & $2733.33 \pm 18.12^{\mathrm{a}}$ \\
\hline & 6 days & $1098.13 \pm 11.32^{\mathrm{a}}$ & $1530.24 \pm 22.24$ & $2627.90 \pm 18.79$ \\
\hline \multirow[t]{2}{*}{ ST } & 10 days & $1060.73 \pm 11.25^{\mathrm{ab}}$ & $1553.83 \pm 21.93$ & $2614.15 \pm 18.54$ \\
\hline & 14 days & $1074.71 \pm 11.21^{\mathrm{b}}$ & $1530.56 \pm 21.86$ & $2605.96 \pm 18.48$ \\
\hline \multirow[t]{10}{*}{ SP } & Control & $1054.42 \pm 9.19^{\mathrm{b}}$ & $1514.96 \pm 18.01^{b}$ & $2567.93 \pm 15.22^{\mathrm{b}}$ \\
\hline & SPIDES & $1101.30 \pm 9.19^{\mathrm{a}}$ & $1561.46 \pm 17.93^{\mathrm{a}}$ & $2664.07 \pm 15.16^{\mathrm{a}}$ \\
\hline & $P \times 6 d \times C$ & $1091.56 \pm 26.85^{\mathrm{abcd}}$ & $1503.66 \pm 53.06^{\mathrm{bcd}}$ & $2741.76 \pm 44.84^{\text {efg }}$ \\
\hline & $P \times 6 d \times S P$ & $1170.23 \pm 28.62^{\mathrm{a}}$ & $1561.66 \pm 56.72^{\mathrm{bc}}$ & $2592.01 \pm 47.94^{\mathrm{bcd}}$ \\
\hline & $P \times 10 d \times C$ & $1043.75 \pm 27.99^{\text {bcdef }}$ & $1566.50 \pm 55.42^{b c}$ & $2608.89 \pm 44.84^{\mathrm{defg}}$ \\
\hline & $P \times 10 d \times S P$ & $1115.86 \pm 26.85^{\mathrm{abc}}$ & $1660.62 \pm 53.06^{\mathrm{ab}}$ & $2775.34 \pm 47.94^{\mathrm{bc}}$ \\
\hline & $\mathrm{P} \times 14 \mathrm{~d} \times \mathrm{C}$ & $1057.11 \pm 26.85^{\text {bcde }}$ & $1585.13 \pm 51.99^{a b c}$ & $2642.24 \pm 46.84^{\text {cdef }}$ \\
\hline & $P \times 14 d \times S P$ & $1112.05 \pm 26.85^{\mathrm{abc}}$ & $1327.00 \pm 53.06^{\mathrm{e}}$ & $2442.10 \pm 44.84^{\mathrm{hij}}$ \\
\hline & $\mathrm{O} \times 6 \mathrm{~d} \times \mathrm{C}$ & $1128.72 \pm 26.85^{\mathrm{ab}}$ & $1530.37 \pm 53.06^{\mathrm{bcd}}$ & $2652.68 \pm 44.84^{\text {cdef }}$ \\
\hline & $\mathrm{O} \times 6 \mathrm{~d} \times \mathrm{SP}$ & $1150.65 \pm 27.40^{\mathrm{a}}$ & $1668.54 \pm 53.06^{\mathrm{ab}}$ & $2819.19 \pm 44.84^{\mathrm{ab}}$ \\
\hline \multirow{10}{*}{$\mathbf{F A} \times \mathbf{S T} \times \mathbf{S P}$} & $\mathrm{O} \times 10 \mathrm{~d} \times \mathrm{C}$ & $1113.05 \pm 27.40^{\mathrm{abc}}$ & $1539.79 \pm 53.06^{\mathrm{bc}}$ & $2652.84 \pm 44.84^{\text {cdef }}$ \\
\hline & $\mathrm{O} \times 10 \mathrm{~d} \times \mathrm{SP}$ & $1165.10 \pm 26.85^{\mathrm{a}}$ & $1487.60 \pm 51.99^{\text {bcde }}$ & $2652.70 \pm 43.94^{\text {cdef }}$ \\
\hline & $\mathrm{O} \times 10 \mathrm{~d} \times \mathrm{C}$ & $1094.75 \pm 26.85^{\mathrm{abcd}}$ & $1608.32 \pm 51.99^{\mathrm{ab}}$ & $2703.07 \pm 43.94^{\text {bcde }}$ \\
\hline & $\mathrm{O} \times 10 \mathrm{~d} \times \mathrm{SP}$ & $1172.74 \pm 26.85^{\mathrm{a}}$ & $1746.78 \pm 51.99^{a}$ & $2919.53 \pm 43.94^{\mathrm{a}}$ \\
\hline & $\mathrm{Y} \times 6 \mathrm{~d} \times \mathrm{C}$ & $1016.16 \pm 27.99^{\mathrm{def}}$ & $1417.80 \pm 55.42^{\text {cde }}$ & $2430.87 \pm 46.84^{\mathrm{ij}}$ \\
\hline & $\mathrm{Y} \times 6 \mathrm{~d} \times \mathrm{SP}$ & $1031.47 \pm 28.62^{\text {cdef }}$ & $1499.39 \pm 55.42^{\mathrm{bcd}}$ & $2530.87 \pm 46.84^{\text {fghi }}$ \\
\hline & $\mathrm{Y} \times 10 \mathrm{~d} \times \mathrm{C}$ & $956.67 \pm 29.29^{f}$ & $1524.28 \pm 56.72^{\mathrm{bcd}}$ & $2480.95 \pm 47.94^{\text {ghij }}$ \\
\hline & $\mathrm{Y} \times 10 \mathrm{~d} \times \mathrm{SP}$ & $969.97 \pm 26.85^{\mathrm{ef}}$ & $1544.20 \pm 51.99^{\mathrm{bc}}$ & $2514.17 \pm 43.94^{\mathrm{fghi}}$ \\
\hline & $\mathrm{Y} \times 14 \mathrm{~d} \times \mathrm{C}$ & $988.01 \pm 27.99^{\text {ef }}$ & $1358.78 \pm 55.42^{\mathrm{de}}$ & $2347.84 \pm 46.84^{j}$ \\
\hline & $\mathrm{Y} \times 14 \mathrm{~d} \times \mathrm{SP}$ & $1023.60 \pm 29.29^{\mathrm{def}}$ & $1557.38 \pm 56.72^{b c}$ & $2580.98 \pm 47.94^{\mathrm{efgh}}$ \\
\hline
\end{tabular}

Mean having similar letters in each column within each effect are not significantly different.

Where; FA= Flock age, $\mathrm{ST}=$ storage period and $\mathrm{SP}=$ short period of incubation during storage (SPIDES)

\section{Feed consumption $(\mathbf{F C})$}

Data presented in table (5) showed that broiler chicks hatched from eggs of prime flock showed higher average FC at the periods of 4-5 and 0-5 weeks of age compared to those hatched from the old and the young flocks. In addition, it is clearly found that chicks hatched form eggs stored for 10 days before incubation was showed highest average of feed consumption compared to those hatched from eggs stored 6 or 14 days before hatching. While, no significant variation were found in feed consumption due to the effect of short period of incubation during storage (SPIDES) applied. Although there is no significant effect was found in FC at the different period of the experiment due to SPIDES treatment, it is clearly observed that chicks hatched from eggs exposed to SPIDES showed less FC than those hatched from untreated one. Regarding to the interaction effects among the studied factors, a significant differences was found in FC due to the interaction effects, it is clearly observed that chicks hatched from eggs of old flock, stored for 10 days and treated with SPIDES showed the highest average of 
FC (4086.56g) at the whole period of the experiment

(0-5wks) compared to the other treatments applied.

Table 5. least- square means and standard error $(\overline{\mathrm{X}} \pm \mathrm{S}$. E) for feed consumption (g/bird) of different experimental groups as affected by studied factors

\begin{tabular}{|c|c|c|c|c|}
\hline \multicolumn{2}{|c|}{ Items } & \multicolumn{3}{|c|}{ feed consumption (g/bird) during } \\
\hline & & 0 - 3 WKS & $3-5$ WKS & 0 - 5 WKS \\
\hline \multirow{3}{*}{ FA } & Young & $1513.28 \pm 23.08$ & $2234.62 \pm 23.08^{b}$ & $3747.90 \pm 23.08^{c}$ \\
\hline & Prime & $1561.26 \pm 23.08$ & $2360.84 \pm 23.08^{\mathrm{a}}$ & $3922.10 \pm 23.08^{\mathrm{a}}$ \\
\hline & Old & $1525.39 \pm 23.08$ & $2314.22 \pm 23.08^{\mathrm{a}}$ & $3839.61 \pm 23.08^{\mathrm{b}}$ \\
\hline \multirow{3}{*}{ ST } & 6 days & $1530.61 \pm 23.08$ & $2278.32 \pm 23.08$ & $3808.93 \pm 23.08^{b}$ \\
\hline & 10 days & $1552.90 \pm 23.08$ & $2329.17 \pm 23.08$ & $3882.08 \pm 23.08^{\mathrm{a}}$ \\
\hline & 14 days & $1516.42 \pm 23.08$ & $2302.18 \pm 23.08$ & $3818.61 \pm 23.08^{\mathrm{ab}}$ \\
\hline \multirow[t]{10}{*}{ SP } & Control & $1556.26 \pm 18.84$ & $2289.86 \pm 18.84$ & $3846.13 \pm 18.84$ \\
\hline & SPIDES & $1510.36 \pm 18.84$ & $2316.59 \pm 18.84$ & $3826.95 \pm 18.84$ \\
\hline & $P \times 6 d \times C$ & $1641.71 \pm 56.54^{\mathrm{ab}}$ & $2257.53 \pm 56.54^{\mathrm{defg}}$ & $3899.24 \pm 56.54^{\mathrm{abc}}$ \\
\hline & $P \times 6 d \times S P$ & $1680.31 \pm 56.54^{\mathrm{a}}$ & $2298.99 \pm 56.54^{\text {cdefg }}$ & $3979.29 \pm 56.54^{\mathrm{ab}}$ \\
\hline & $P \times 10 d \times C$ & $1487.81 \pm 56.54^{\text {bcde }}$ & $2346.08 \pm 56.54^{\text {abcdef }}$ & $3833.88 \pm 56.54^{\text {bcd }}$ \\
\hline & $P \times 10 d \times S P$ & $1498.70 \pm 56.54^{\mathrm{abcde}}$ & $2246.45 \pm 56.54^{\mathrm{efg}}$ & $3745.15 \pm 56.54^{\text {cde }}$ \\
\hline & $\mathrm{P} \times 14 \mathrm{~d} \times \mathrm{C}$ & $1599.66 \pm 56.54^{\mathrm{abc}}$ & $2436.60 \pm 56.54^{\mathrm{abcd}}$ & $4036.26 \pm 56.54^{\mathrm{a}}$ \\
\hline & $\mathrm{P} \times 14 \mathrm{~d} \times \mathrm{SP}$ & $1459.42 \pm 56.54^{\text {bcde }}$ & $2579.42 \pm 56.54^{\mathrm{a}}$ & $4038.83 \pm 56.54^{\mathrm{a}}$ \\
\hline & $\mathrm{O} \times 6 \mathrm{~d} \times \mathrm{C}$ & $1535.47 \pm 56.54^{\mathrm{abcd}}$ & $2205.62 \pm 56.54^{\mathrm{fg}}$ & $3741.09 \pm 56.54^{\text {cde }}$ \\
\hline & $\mathrm{O} \times 6 \mathrm{~d} \times \mathrm{SP}$ & $1332.43 \pm 56.54^{\mathrm{e}}$ & $2155.15 \pm 56.54^{\mathrm{g}}$ & $3487.58 \pm 56.54^{\mathrm{fg}}$ \\
\hline \multirow{10}{*}{$\mathbf{F A} \times \mathrm{ST} \times \mathrm{SP}$} & $\mathrm{O} \times 10 \mathrm{~d} \times \mathrm{C}$ & $1514.95 \pm 56.54^{\mathrm{abcde}}$ & $2306.21 \pm 56.54^{\text {cdefg }}$ & $3821.16 \pm 56.54^{\mathrm{bcd}}$ \\
\hline & $\mathrm{O} \times 10 \mathrm{~d} \times \mathrm{SP}$ & $1579.83 \pm 56.54^{\mathrm{abcd}}$ & $2506.73 \pm 56.54^{\mathrm{ab}}$ & $4086.56 \pm 56.54^{\mathrm{a}}$ \\
\hline & $\mathrm{O} \times 10 \mathrm{~d} \times \mathrm{C}$ & $1640.08 \pm 56.54^{\mathrm{ab}}$ & $2316.38 \pm 56.54^{\text {cdefg }}$ & $3956.47 \pm 56.54^{\mathrm{ab}}$ \\
\hline & $\mathrm{O} \times 10 \mathrm{~d} \times \mathrm{SP}$ & $1549.59 \pm 56.54^{\mathrm{abcd}}$ & $2395.23 \pm 56.54^{\text {abcdef }}$ & $3944.81 \pm 56.54^{\mathrm{ab}}$ \\
\hline & $\mathrm{Y} \times 6 \mathrm{~d} \times \mathrm{C}$ & $1578.54 \pm 56.54^{\mathrm{abcd}}$ & $2460.85 \pm 56.54^{\mathrm{abc}}$ & $4039.39 \pm 56.54^{\mathrm{a}}$ \\
\hline & $\mathrm{Y} \times 6 \mathrm{~d} \times \mathrm{SP}$ & $1415.20 \pm 56.54^{\mathrm{cde}}$ & $2291.79 \pm 56.54^{\text {cdefg }}$ & $3706.99 \pm 56.54^{\mathrm{ed}}$ \\
\hline & $\mathrm{Y} \times 10 \mathrm{~d} \times \mathrm{C}$ & $1555.34 \pm 56.54^{\mathrm{abcd}}$ & $2403.56 \pm 56.54^{\mathrm{abcde}}$ & $3958.90 \pm 56.54^{\mathrm{ab}}$ \\
\hline & $\mathrm{Y} \times 10 \mathrm{~d} \times \mathrm{SP}$ & $1680.81 \pm 56.54^{\mathrm{a}}$ & $2166.04 \pm 56.54^{\mathrm{g}}$ & $3846.86 \pm 56.54^{\mathrm{bcd}}$ \\
\hline & $\mathrm{Y} \times 14 \mathrm{~d} \times \mathrm{C}$ & $1452.85 \pm 56.54^{\text {bcde }}$ & $1875.94 \pm 56.54^{\mathrm{h}}$ & $3328.79 \pm 56.54^{\mathrm{g}}$ \\
\hline & $\mathrm{Y} \times 14 \mathrm{~d} \times \mathrm{SP}$ & $1396.95 \pm 56.54^{\mathrm{ed}}$ & $2209.56 \pm 56.54^{\mathrm{fg}}$ & $3606.51 \pm 56.54^{\mathrm{ef}}$ \\
\hline
\end{tabular}

Mean having similar letters in each column within each effect are not significantly different.

Whereas; FA= Flock age, $\mathrm{ST}=$ storage period and $\mathrm{SP}=$ short period of incubation during storage (SPIDES)

\section{Feed conversion rate $(\mathrm{FCR})$}

The obtained results showed in table (6) revealed that broiler chicks hatched from eggs of old flock showed significant improvement in average FCR (1.40 $\mathrm{g}$ feed/g gain) followed by those hatched from the prime and young flocks were $(1.49$ and $1.51 \mathrm{~g}$ feed/g gain, respectively) at the whole period of the experiment (0-5 weeks). In addition, chicks hatched form eggs stored for 6 days before incubation showed the highest average of FCR (1.45 $\mathrm{g}$ feed/g gain) compared to those hatched from eggs stored 14 or 10 days, respectively. This result may quite logic sense the storage of eggs beyond 7 days decrease chick quality on the day hatch (Tona et al., 2004), decrease FCR and decrease the growth performance subsequently (Tona et al., 2004). Regarding to, the effect of short period of incubation during storage (SPIDES), significant variations were found in FCR due to the effect of SPIDES treatment. Chicks hatched from eggs exposed to SPIDES showed higher improvement in average FCR mounted $(1.44 \mathrm{~g}$ feed $/ \mathrm{g}$ gain) than those hatched from untreated one (1.49 $\mathrm{g}$ feed/g gain). Concerning to, the interaction effects among the studied factors on FCR, it is quite clear that there were a significant differences in average FCR due to the interaction effects. Chicks hatched from eggs of old flock, stored for 6 days and treated with SPIDES had showed the highest average FCR (1.23 g feed/g gain) at the whole period of the experiment (0$5 \mathrm{wks}$ ) compared to the other interaction effects among studied factors. 
Table 6. Least_square means and standard error $(\bar{X} \pm S . E)$ for feed conversion ( $\mathrm{g}$ feed/g gain) of different experimental groups as affected by studied factors

\begin{tabular}{|c|c|c|c|c|}
\hline \multirow{2}{*}{\multicolumn{2}{|c|}{ Items }} & \multicolumn{3}{|c|}{ feed conversion ( $\mathrm{g}$ feed/g gain)during } \\
\hline & & 0 - 3 WKS & 3-5 WKS & 0 - 5 WKS \\
\hline \multirow{3}{*}{ FA } & Young & $1.52 \pm 0.009^{\mathrm{a}}$ & $1.50 \pm 0.009^{\mathrm{b}}$ & $1.51 \pm 0.004^{\mathrm{a}}$ \\
\hline & Prime & $1.42 \pm 0.009^{b}$ & $1.55 \pm 0.009^{\mathrm{a}}$ & $1.49 \pm 0.004^{\mathrm{b}}$ \\
\hline & Old & $1.34 \pm 0.009^{\mathrm{c}}$ & $1.45 \pm 0.009^{c}$ & $1.40 \pm 0.004^{\mathrm{c}}$ \\
\hline \multirow{3}{*}{ ST } & 6 days & $1.39 \pm 0.009^{\mathrm{b}}$ & $1.49 \pm 0.009^{\mathrm{a}}$ & $1.45 \pm 0.004^{\mathrm{c}}$ \\
\hline & 10 days & $1.47 \pm 0.009^{\mathrm{a}}$ & $1.50 \pm 0.009^{\mathrm{a}}$ & $1.48 \pm 0.004^{\mathrm{a}}$ \\
\hline & 14 days & $1.41 \pm 0.009^{\mathrm{b}}$ & $1.51 \pm 0.009^{\mathrm{a}}$ & $1.46 \pm 0.004^{\mathrm{b}}$ \\
\hline \multirow[b]{12}{*}{$\mathbf{F A} \times \mathbf{S T} \times \mathbf{S P}$} & Control & $1.48 \pm 0.008^{\mathrm{a}}$ & $1.51 \pm 0.007^{\mathrm{a}}$ & $1.49 \pm 0.003^{\mathrm{a}}$ \\
\hline & SPIDES & $1.37 \pm 0.008^{\mathrm{b}}$ & $1.49 \pm 0.007^{\mathrm{a}}$ & $1.44 \pm 0.003^{\mathrm{b}}$ \\
\hline & $P \times 6 d \times C$ & $1.50 \pm 0.02^{\mathrm{cd}}$ & $1.50 \pm 0.022^{\mathrm{de}}$ & $1.50 \pm 0.011^{\mathrm{d}}$ \\
\hline & $P \times 6 d \times S P$ & $1.43 \pm 0.02^{\mathrm{def}}$ & $1.47 \pm 0.022^{\text {def }}$ & $1.45 \pm 0.011^{\mathrm{e}}$ \\
\hline & $P \times 10 d \times C$ & $1.42 \pm 0.02^{\mathrm{efg}}$ & $1.49 \pm 0.022^{\mathrm{de}}$ & $1.46 \pm 0.011^{\mathrm{e}}$ \\
\hline & $\mathrm{P} \times 10 \mathrm{~d} \times \mathrm{SP}$ & $1.34 \pm 0.02^{\mathrm{h}}$ & $1.35 \pm 0.022^{\mathrm{hi}}$ & $1.34 \pm 0.011^{\mathrm{h}}$ \\
\hline & $\mathrm{P} \times 14 \mathrm{~d} \times \mathrm{C}$ & $1.51 \pm 0.02^{\mathrm{cd}}$ & $1.53 \pm 0.022^{\mathrm{cd}}$ & $1.52 \pm 0.011^{\mathrm{cd}}$ \\
\hline & $\mathrm{P} \times 14 \mathrm{~d} \times \mathrm{SP}$ & $1.31 \pm 0.02^{\mathrm{h}}$ & $1.95 \pm 0.022^{\mathrm{a}}$ & $1.65 \pm 0.011^{\mathrm{a}}$ \\
\hline & $\mathrm{O} \times 6 \mathrm{~d} \times \mathrm{C}$ & $1.36 \pm 0.02^{\mathrm{fgh}}$ & $1.44 \pm 0.022^{\text {efg }}$ & $1.41 \pm 0.011^{\mathrm{fg}}$ \\
\hline & $\mathrm{O} \times 6 \mathrm{~d} \times \mathrm{SP}$ & $1.15 \pm 0.02^{\mathrm{h}}$ & $1.29 \pm 0.022^{\mathrm{i}}$ & $1.23 \pm 0.011^{\mathrm{i}}$ \\
\hline & $\mathrm{O} \times 10 \mathrm{~d} \times \mathrm{C}$ & $1.36 \pm 0.02^{\text {fgh }}$ & $1.49 \pm 0.022^{\mathrm{de}}$ & $1.44 \pm 0.011^{\mathrm{ef}}$ \\
\hline & $\mathrm{O} \times 10 \mathrm{~d} \times \mathrm{SP}$ & $1.35 \pm 0.02^{\mathrm{fgh}}$ & $1.68 \pm 0.022^{b}$ & $1.54 \pm 0.011^{\mathrm{c}}$ \\
\hline \multirow{8}{*}{$\mathbf{F A} \times \mathbf{S T} \times \mathbf{S P}$} & $\mathrm{O} \times 10 \mathrm{~d} \times \mathrm{C}$ & $1.49 \pm 0.02^{\mathrm{cde}}$ & $1.44 \pm 0.022^{\mathrm{efg}}$ & $1.46 \pm 0.011^{\mathrm{e}}$ \\
\hline & $\mathrm{O} \times 10 \mathrm{~d} \times \mathrm{SP}$ & $1.32 \pm 0.02^{\mathrm{h}}$ & $1.37 \pm 0.022^{\mathrm{gh}}$ & $1.35 \pm 0.011^{\mathrm{h}}$ \\
\hline & $\mathrm{Y} \times 6 \mathrm{~d} \times \mathrm{C}$ & $1.55 \pm 0.02^{\mathrm{c}}$ & $1.73 \pm 0.022^{b}$ & $1.66 \pm 0.011^{\mathrm{a}}$ \\
\hline & $\mathrm{Y} \times 6 \mathrm{~d} \times \mathrm{SP}$ & $1.37 \pm 0.02^{\mathrm{fgh}}$ & $1.52 \pm 0.022^{\mathrm{cd}}$ & $1.46 \pm 0.011^{\mathrm{e}}$ \\
\hline & $\mathrm{Y} \times 10 \mathrm{~d} \times \mathrm{C}$ & $1.63 \pm 0.02^{\mathrm{b}}$ & $1.57 \pm 0.022^{\mathrm{c}}$ & $1.59 \pm 0.011^{\mathrm{b}}$ \\
\hline & $\mathrm{Y} \times 10 \mathrm{~d} \times \mathrm{SP}$ & $1.73 \pm 0.02^{\mathrm{a}}$ & $1.40 \pm 0.022^{\mathrm{fgh}}$ & $1.53 \pm 0.011^{\mathrm{cd}}$ \\
\hline & $\mathrm{Y} \times 14 \mathrm{~d} \times \mathrm{C}$ & $1.47 \pm 0.02^{\mathrm{de}}$ & $1.38 \pm 0.022^{\mathrm{gh}}$ & $1.41 \pm 0.011^{\mathrm{fg}}$ \\
\hline & $\mathrm{Y} \times 14 \mathrm{~d} \times \mathrm{SP}$ & $1.36 \pm 0.02^{\mathrm{fgh}}$ & $1.41 \pm 0.022^{\text {fgh }}$ & $1.39 \pm 0.011^{\mathrm{g}}$ \\
\hline
\end{tabular}

Mean having similar letters in each column within each effect are not significantly different.

Whereas; $\mathrm{FA}=$ Flock age, $\mathrm{ST}=$ storage period and $\mathrm{SP}=$ short period of incubation during storage (SPIDES)

\section{Mortality rate (MR)}

Data presented in table (7) showed that chicks hatched from eggs of old flock showed significant lower average mortality rate $(\mathrm{MR})$ mounted $(0.33 \%)$ compared to those hatched from the prime and young flocks were (1.0 and $2.16 \%$, respectively) at the whole period of the experiment (0-5 weeks). Regarding to the effect of storage period of incubated eggs on mortality percentage of post hatched chicks. It is clearly found that chicks hatched form eggs stored for 14 days before incubation showed the lowest average of MR $(0.83 \%)$ compared to those hatched from eggs stored for 6 or 10 days (1.0 and 1.66\%), respectively. This result was quite differs to the embryonic mortality during the incubation, sense the conditions of rearing period of grower chicks in the farm differ from the conditions during incubation. Moreover, the short period of incubation during storage (SPIDES) has significant effect on mortality rate during the rearing period of chicks. Chicks hatched from eggs exposed to SPIDES showed lower MR $(1.11 \%)$ than those hatched from untreated one $(1.22 \%)$. Concerning to, the interaction effects among the studied factors on MR, although there was a significant difference in average MR without specific trend due to the interaction effects. It is obvious that, mostly the chicks hatched from eggs treated with SPIDES and affected with the flock age and period of storage as well showed lower MR compared to the other interaction effects without applying SPIDES at the whole period of the experiment (0-5wks).

\section{Performance index (PI)}

Chicks hatched from eggs of old flock showed significant higher average performance index (PI) was (198.88\%) compared to those hatched from the prime and young flocks were (180.39 and $167.23 \%$, respectively) at the whole period of the experiment $(0$ 5 weeks).this result goes in the same trend of both live body weight (LBW) and feed conversion ratio (FCR) sense PI \%calculated from dividing LBW on FCR in the same period of the experiment. No significant variations were found in average of PI of grower chicks due to the effect of both storage periods of incubated eggs or SPIDES treatments. However, significant variations were found in average of PI \% due to the interaction effect among studied factors. Chicks hatched from eggs of old flock, stored for 6 days and treated with SPIDES showed the highest average of PI $(231.73 \%)$ compared to the other interaction effects at the whole period of the experiment (table, 7 ). 
Table 7. least_square means and standard error $(\bar{X} \pm S$. E) for mortality rate $(\%)$ during and performance index (\%) of different experimental groups as affected by studied factors

\begin{tabular}{|c|c|c|c|}
\hline \multicolumn{2}{|c|}{ Items } & \multirow{2}{*}{$\begin{array}{r}\begin{array}{c}\text { Mortality rate } \\
(\%) \text { during } \\
(\mathbf{0 - 5} \text { WKS })\end{array} \\
2.16 \pm 0.00^{\mathrm{a}}\end{array}$} & \multirow{2}{*}{$\begin{array}{c}\begin{array}{c}\text { Performance index }(\%) \\
\text { during } \\
(\mathbf{0 - 5} \text { WKS })\end{array} \\
167.23 \pm 9.36^{\mathrm{b}}\end{array}$} \\
\hline \multirow{3}{*}{ FA } & Young & & \\
\hline & Prime & $1.00 \pm 0.00^{\mathrm{b}}$ & $180.39 \pm 9.36^{\mathrm{ab}}$ \\
\hline & Old & $0.33 \pm 0.00^{\mathrm{c}}$ & $198.88 \pm 9.36^{\mathrm{a}}$ \\
\hline \multirow{3}{*}{ ST } & 6 days & $1.00 \pm 0.00^{\mathrm{b}}$ & $186.54 \pm 9.36^{\mathrm{a}}$ \\
\hline & 10 days & $1.66 \pm 0.00^{\mathrm{a}}$ & $178.53 \pm 9.36^{\mathrm{a}}$ \\
\hline & 14 days & $0.83 \pm 0.00^{\mathrm{c}}$ & $181.43 \pm 9.36^{\mathrm{a}}$ \\
\hline \multirow[b]{12}{*}{ FA $\times S T \times S P$} & Control & $1.22 \pm 0.00^{\mathrm{a}}$ & $175.16 \pm 7.64^{\mathrm{a}}$ \\
\hline & SPIDES & $1.11 \pm 0.00^{\mathrm{b}}$ & $189.17 \pm 7.64^{\mathrm{a}}$ \\
\hline & $P \times 6 d \times C$ & $1.00 \pm 0.00^{\mathrm{e}}$ & $179.48 \pm 22.93^{\mathrm{ab}}$ \\
\hline & $P \times 6 d \times S P$ & $3.00 \pm 0.00^{\mathrm{c}}$ & $192.92 \pm 22.93^{\mathrm{ab}}$ \\
\hline & $P \times 10 d \times C$ & $1.00 \pm 0.00^{\mathrm{e}}$ & $180.33 \pm 22.93^{\mathrm{ab}}$ \\
\hline & $P \times 10 d \times S P$ & $1.00 \pm 0.00^{\mathrm{e}}$ & $203.79 \pm 22.93^{\mathrm{ab}}$ \\
\hline & $\mathrm{P} \times 14 \mathrm{~d} \times \mathrm{C}$ & $0.00 \pm 0.00^{\mathrm{f}}$ & $175.66 \pm 22.93^{\mathrm{ab}}$ \\
\hline & $P \times 14 d \times S P$ & $0.00 \pm 0.00^{\mathrm{f}}$ & $150.16 \pm 22.93^{\mathrm{b}}$ \\
\hline & $\mathrm{O} \times 6 \mathrm{~d} \times \mathrm{C}$ & $1.00 \pm 0.00^{\mathrm{e}}$ & $191.45 \pm 22.93^{\mathrm{ab}}$ \\
\hline & $\mathrm{O} \times 6 \mathrm{~d} \times \mathrm{SP}$ & $0.00 \pm 0.00^{\mathrm{f}}$ & $231.73 \pm 22.93^{\mathrm{a}}$ \\
\hline & $\mathrm{O} \times 10 \mathrm{~d} \times \mathrm{C}$ & $1.00 \pm 0.00^{\mathrm{e}}$ & $187.45 \pm 22.93^{\mathrm{ab}}$ \\
\hline & $\mathrm{O} \times 10 \mathrm{~d} \times \mathrm{SP}$ & $0.00 \pm 0.00^{\mathrm{f}}$ & $175.26 \pm 22.93^{\mathrm{ab}}$ \\
\hline \multirow{8}{*}{$\mathbf{F A} \times \mathbf{S T} \times \mathbf{S P}$} & $\mathrm{O} \times 10 \mathrm{~d} \times \mathrm{C}$ & $0.00 \pm 0.00^{\mathrm{f}}$ & $187.88 \pm 22.93^{\mathrm{ab}}$ \\
\hline & $\mathrm{O} \times 10 \mathrm{~d} \times \mathrm{SP}$ & $0.00 \pm 0.00^{\mathrm{f}}$ & $219.56 \pm 22.93^{\mathrm{ab}}$ \\
\hline & $\mathrm{Y} \times 6 \mathrm{~d} \times \mathrm{C}$ & $1.00 \pm 0.00^{\mathrm{e}}$ & $148.44 \pm 22.93^{\mathrm{b}}$ \\
\hline & $\mathrm{Y} \times 6 \mathrm{~d} \times \mathrm{SP}$ & $0.00 \pm 0.00^{\mathrm{f}}$ & $175.23 \pm 22.93^{\mathrm{ab}}$ \\
\hline & $\mathrm{Y} \times 10 \mathrm{~d} \times \mathrm{C}$ & $5.00 \pm 0.00^{\mathrm{a}}$ & $157.71 \pm 22.93^{\mathrm{ab}}$ \\
\hline & $\mathrm{Y} \times 10 \mathrm{~d} \times \mathrm{SP}$ & $2.00 \pm 0.00^{\mathrm{d}}$ & $166.66 \pm 22.93^{\mathrm{ab}}$ \\
\hline & $\mathrm{Y} \times 14 \mathrm{~d} \times \mathrm{C}$ & $1.00 \pm 0.00^{\mathrm{e}}$ & $168.10 \pm 22.93^{\mathrm{ab}}$ \\
\hline & $\mathrm{Y} \times 14 \mathrm{~d} \times \mathrm{SP}$ & $4.00 \pm 0.00^{\mathrm{b}}$ & $187.26 \pm 22.93^{\mathrm{ab}}$ \\
\hline
\end{tabular}

Mean having similar letters in each column within each effect are not significantly different.

Whereas; FA= Flock age, $\mathrm{ST}=$ storage period and $\mathrm{SP}=$ short period of incubation during storage (SPIDES)

\section{Carcass traits}

Results obtained in Table (8) showed that absolute weights of carcass weights were significantly differed due to the effect of flock age. Broiler chicks hatched from older flock showed higher average eviscerated, giblets and total edible parts were $(2086.38,132.12$ and 2218.51g, respectively) compared to those showed by chicks of both prime and young flock. This result was seemed quite logic sense the chicks hatched from eggs of old flock resulted the higher average body weight at the different time of estimation and at the end the end of the experiment as well, thus it showed higher averages of carcass traits. However, no significant variations were found in average absolute and relative carcass weights of broiler chicks due to the effect of either storage period or treating with SPIDES of incubated eggs. Concerning to the effect of interaction effect among studied factors on relative and absolute carcass weights of broiler chicks, it is clearly found that chicks hatched from eggs of old flock, stored for 6 days and exposed to SPIDES showed highest average absolute weights of eviscerated and total edible parts mounted 2235.0 and $2365.13 \mathrm{~g}$, respectively compared to the other treatments applied. While, broilers hatched from eggs of old flock, stored for 10 days and without treating with SPIDES showed highest average relative weights of eviscerated and total edible parts were 80.36 and $85.17 \%$, respectively compared to the other experimental groups. However, those hatched form eggs of old flock, stored for 10 days and untreated with SPIDES showed highest average absolute and relative of giblets were (141.66g and $5.22 \%$, respectively). 
Table 8. least_square means and standard error $(\bar{X} \pm S$. E) for feed conversion ( $g$ feed/g gain) of different experimental groups as affected by studied factors

\begin{tabular}{|c|c|c|c|c|c|c|c|}
\hline \multicolumn{2}{|c|}{ Items } & \multicolumn{6}{|c|}{ Weights of carcass traits } \\
\hline & & \multicolumn{2}{|c|}{ Eviscerated } & \multicolumn{2}{|c|}{ Giblets } & \multicolumn{2}{|c|}{ Total edible parts } \\
\hline & & g & $\%$ & $\mathbf{g}$ & $\%$ & g & $\%$ \\
\hline \multirow{4}{*}{ FA } & Young & $1817.77 \pm 43.8^{b}$ & $72.06 \pm 2.02^{\mathrm{a}}$ & $114.45 \pm 3.68^{b}$ & $4.53 \pm 0.15^{\mathrm{a}}$ & $1932.23 \pm 45.28^{b}$ & $76.60 \pm 2.10^{\mathrm{a}}$ \\
\hline & Prime & $2001.66 \pm 43.8^{\mathrm{a}}$ & $75.11 \pm 2.02^{\mathrm{a}}$ & $121.35 \pm 3.68^{b}$ & $4.54 \pm 0.15^{\mathrm{a}}$ & $2123.02 \pm 45.28^{\mathrm{a}}$ & $79.65 \pm 2.10^{\mathrm{a}}$ \\
\hline & Old & $2086.38 \pm 43.8^{\mathrm{a}}$ & $73.89 \pm 2.02^{\mathrm{a}}$ & $132.12 \pm 3.68^{\mathrm{a}}$ & $4.67 \pm 0.15^{\mathrm{a}}$ & $2218.51 \pm 45.28^{a}$ & $78.56 \pm 2.10^{\mathrm{a}}$ \\
\hline & 6 days & $1977.77 \pm 43.8^{\mathrm{a}}$ & $73.10 \pm 2.02^{\mathrm{a}}$ & $123.31 \pm 3.68^{\mathrm{a}}$ & $4.54 \pm 0.15^{\mathrm{a}}$ & $2101.08 \pm 45.28^{\mathrm{a}}$ & $77.64 \pm 2.10^{\mathrm{a}}$ \\
\hline \multirow[t]{2}{*}{ ST } & 10 days & $1980.00 \pm 43.8^{\mathrm{a}}$ & $74.72 \pm 2.02^{\mathrm{a}}$ & $121.95 \pm 3.68^{\mathrm{a}}$ & $4.61 \pm 0.15^{\mathrm{a}}$ & $2101.95 \pm 45.28^{\mathrm{a}}$ & $79.34 \pm 2.10^{\mathrm{a}}$ \\
\hline & 14 days & $1948.05 \pm 43.8^{\mathrm{a}}$ & $73.23 \pm 2.02^{\mathrm{a}}$ & $122.67 \pm 3.68^{\mathrm{a}}$ & $4.59 \pm 0.15^{\mathrm{a}}$ & $2070.72 \pm 45.28^{\mathrm{a}}$ & $77.83 \pm 2.10^{\mathrm{a}}$ \\
\hline \multirow[t]{11}{*}{ SP } & Control & $1944.44 \pm 35.7^{\mathrm{a}}$ & $73.72 \pm 1.65^{\mathrm{a}}$ & $120.61 \pm 3.00^{\mathrm{a}}$ & $4.56 \pm 0.12^{\mathrm{a}}$ & $2065.05 \pm 36.97^{\mathrm{a}}$ & $78.28 \pm 1.71^{\mathrm{a}}$ \\
\hline & SPIDES & $1992.77 \pm 35.7^{\mathrm{a}}$ & $73.65 \pm 1.65^{\mathrm{a}}$ & $124.68 \pm 3.00^{\mathrm{a}}$ & $4.60 \pm 0.12^{\mathrm{a}}$ & $2117.45 \pm 36.97^{\mathrm{a}}$ & $78.26 \pm 1.71^{\mathrm{a}}$ \\
\hline & $P \times 6 d \times C$ & $1955.0 \pm 107.29^{\mathrm{abcd}}$ & $75.04 \pm 4.95^{\mathrm{ab}}$ & $117.80 \pm 9.02^{\mathrm{abc}}$ & $4.52 \pm 0.38^{\mathrm{a}}$ & $2072.80 \pm 110.9^{\text {abcd }}$ & $79.55 \pm 5.15^{\mathrm{ab}}$ \\
\hline & $\begin{array}{l}P \times 6 d \times \\
S P\end{array}$ & $2093.3 \pm 107.29^{\mathrm{abc}}$ & $75.39 \pm 4.95^{\mathrm{ab}}$ & $129.10 \pm 9.02^{\mathrm{abc}}$ & $4.64 \pm 0.38^{\mathrm{a}}$ & $2222.43 \pm 110.9^{\mathrm{abc}}$ & $80.04 \pm 5.15^{\mathrm{ab}}$ \\
\hline & $\begin{array}{l}\mathrm{P} \times 10 \mathrm{~d} \times \\
C\end{array}$ & $2015.0 \pm 107.29^{\mathrm{abcd}}$ & $76.03 \pm 4.95^{\mathrm{ab}}$ & $123.86 \pm 9.02^{\mathrm{abc}}$ & $4.68 \pm 0.38^{\mathrm{a}}$ & $2138.86 \pm 110.9^{\mathrm{abcd}}$ & $80.72 \pm 5.15^{\mathrm{ab}}$ \\
\hline & $\begin{array}{l}P \times 10 \mathrm{~d} \times \\
S P\end{array}$ & $2130.0 \pm 107.29^{\mathrm{abc}}$ & $75.67 \pm 4.95^{\mathrm{ab}}$ & $134.73 \pm 9.02^{\mathrm{ab}}$ & $4.78 \pm 0.38^{\mathrm{a}}$ & $2264.73 \pm 110.9^{\mathrm{abc}}$ & $80.46 \pm 5.15^{\mathrm{ab}}$ \\
\hline & $\begin{array}{l}\mathrm{P} \times 14 \mathrm{~d} \times \\
\mathrm{C}\end{array}$ & $1960.0 \pm 107.29^{\mathrm{abcd}}$ & $73.22 \pm 4.95^{\mathrm{ab}}$ & $109.73 \pm 9.02^{\mathrm{bc}}$ & $4.05 \pm 0.38^{\mathrm{a}}$ & $2069.73 \pm 110.9^{\mathrm{abcd}}$ & $77.27 \pm 5.15^{\mathrm{ab}}$ \\
\hline & $\begin{array}{l}\mathrm{P} \times 14 \mathrm{~d} \times \\
\mathrm{SP}\end{array}$ & $1856.6 \pm 107.29^{\mathrm{bcd}}$ & $75.31 \pm 4.95^{\mathrm{ab}}$ & $112.92 \pm 9.02^{\mathrm{abc}}$ & $4.57 \pm 0.38^{\mathrm{a}}$ & $1969.59 \pm 110.9^{\mathrm{bcd}}$ & $79.88 \pm 5.15^{\mathrm{ab}}$ \\
\hline & $O \times 6 d \times$ & $1871.6 \pm 107.29^{\mathrm{bcd}}$ & $61.87 \pm 4.95^{\mathrm{b}}$ & $136.80 \pm 9.02^{\mathrm{ab}}$ & $4.50 \pm 0.38^{\mathrm{a}}$ & $2008.46 \pm 110.9^{\mathrm{abcd}}$ & $66.37 \pm 5.15^{b}$ \\
\hline & $\begin{array}{l}O \times 6 d \times \\
S P\end{array}$ & $2235.0 \pm 107.29^{\mathrm{a}}$ & $78.17 \pm 4.95^{\mathrm{ab}}$ & $130.13 \pm 9.02^{\mathrm{abc}}$ & $4.54 \pm 0.38^{\mathrm{a}}$ & $2365.13 \pm 110.9^{\mathrm{a}}$ & $82.71 \pm 5.15^{\mathrm{ab}}$ \\
\hline & $\mathrm{O} \times 10 \mathrm{~d} \times$ & $2165.0 \pm 107.29^{\mathrm{abc}}$ & $80.36 \pm 4.95^{\mathrm{a}}$ & $128.50 \pm 9.02^{\mathrm{abc}}$ & $4.80 \pm 0.38^{\mathrm{a}}$ & $2293.50 \pm 110.9^{\mathrm{abc}}$ & $85.17 \pm 5.15^{\mathrm{a}}$ \\
\hline \multirow[t]{9}{*}{$\mathrm{FA} \times \mathrm{ST} \times \mathrm{SP}$} & $\begin{array}{l}\text { O } \times 10 d \times \\
\text { SP }\end{array}$ & $2008.3 \pm 107.29^{\mathrm{abcd}}$ & $74.55 \pm 4.95^{\mathrm{ab}}$ & $119.00 \pm 9.02^{\mathrm{abc}}$ & $4.42 \pm 0.38^{\mathrm{a}}$ & $2127.33 \pm 110.9^{\text {abcd }}$ & $78.97 \pm 5.15^{\mathrm{ab}}$ \\
\hline & $\begin{array}{l}O \\
C\end{array}$ & $2040.0 \pm 107.29^{\mathrm{abcd}}$ & $74.77 \pm 4.95^{\mathrm{ab}}$ & $141.66 \pm 9.02^{\mathrm{a}}$ & $5.22 \pm 0.38^{\mathrm{a}}$ & $2181.66 \pm 110.9^{\mathrm{abcd}}$ & $80.00 \pm 5.15^{\mathrm{ab}}$ \\
\hline & $\begin{array}{l}\mathrm{O} \times 10 \mathrm{~d} \times \\
\mathrm{SP}\end{array}$ & $2198.3 \pm 107.29^{\mathrm{ab}}$ & $73.60 \pm 4.95^{\mathrm{ab}}$ & $136.63 \pm 9.02^{\mathrm{ab}}$ & $4.56 \pm 0.38^{\mathrm{a}}$ & $2334.96 \pm 110.9^{\mathrm{ab}}$ & $78.17 \pm 5.15^{\mathrm{ab}}$ \\
\hline & $\begin{array}{l}Y \times 6 d \times \\
C\end{array}$ & $1848.3 \pm 107.29^{\mathrm{bcd}}$ & $75.48 \pm 4.95^{\mathrm{ab}}$ & $103.03 \pm 9.02^{\mathrm{c}}$ & $4.20 \pm 0.38^{\mathrm{a}}$ & $1951.36 \pm 110.9^{\text {cd }}$ & $79.68 \pm 5.15^{\mathrm{ab}}$ \\
\hline & $\begin{array}{l}Y \times 6 d \times \\
S P\end{array}$ & $1863.3 \pm 107.29^{\mathrm{bcd}}$ & $72.66 \pm 4.95^{\mathrm{ab}}$ & $123.00 \pm 9.02^{\mathrm{abc}}$ & $4.83 \pm 0.38^{\mathrm{a}}$ & $1986.33 \pm 110.9^{\mathrm{bcd}}$ & $77.49 \pm 5.15^{\mathrm{ab}}$ \\
\hline & $\begin{array}{l}\mathrm{Y} \times 10 \mathrm{~d} \times \\
C\end{array}$ & $1841.6 \pm 107.29^{\mathrm{bcd}}$ & $73.13 \pm 4.95^{\mathrm{ab}}$ & $112.26 \pm 9.02^{\mathrm{abc}}$ & $4.54 \pm 0.38^{\mathrm{a}}$ & $1953.93 \pm 110.9^{\mathrm{dc}}$ & $77.67 \pm 5.15^{\mathrm{ab}}$ \\
\hline & $\begin{array}{l}Y \times 10 d \times \\
S P\end{array}$ & $1720.0 \pm 107.29^{d}$ & $68.58 \pm 4.95^{\mathrm{ab}}$ & $113.36 \pm 9.02^{\mathrm{abc}}$ & $4.47 \pm 0.38^{\mathrm{a}}$ & $1833.36 \pm 110.9^{d}$ & $73.05 \pm 5.15^{\mathrm{ab}}$ \\
\hline & $\begin{array}{l}Y \times 14 d \times \\
C\end{array}$ & $1803.3 \pm 107.29^{\mathrm{cd}}$ & $73.58 \pm 4.95^{\mathrm{ab}}$ & $111.83 \pm 9.02^{\mathrm{abc}}$ & $4.55 \pm 0.38^{\mathrm{a}}$ & $1915.16 \pm 110.9^{\mathrm{cd}}$ & $78.14 \pm 5.15^{\mathrm{ab}}$ \\
\hline & $\begin{array}{l}Y \times 14 d \times \\
S P\end{array}$ & $1830.0 \pm 107.29^{\mathrm{cd}}$ & $68.92 \pm 4.95^{\mathrm{ab}}$ & $123.23 \pm 9.02^{\mathrm{abc}}$ & $4.62 \pm 0.38^{\mathrm{a}}$ & $1953.23 \pm 110.9^{\mathrm{cd}}$ & $73.55 \pm 5.15^{\mathrm{ab}}$ \\
\hline
\end{tabular}

Mean having similar letters in each column within each effect are not significantly different.

Whereas; FA= Flock age, $\mathrm{ST}=$ storage period and $\mathrm{SP}=$ short period of incubation during storage (SPIDES)

\section{Conclusion}

From the obtained results of this study, it could be recommended to treating the incubated eggs with SPIDES to improve the productive performance of broilers. Thus, chicks hatched from old flock, storage for 10 days and exposing to SPIDES seemed to be adequate to achieve the favorable results for improve the productively of broiler chicks.

\section{References}

Alsobayel, A.A., 1992. Effect of protein rearing diet and age on fertility and hatchability parameters of Saudi Arabian Baladi chickens. J. King Saudi Univ., 4: 47-54.
Anderson, P.A., 1985. Interactions between proteins and constituents that affect protein quality. In; Digestibility and amino acid availability in cereals and oil seeds (J.W Finley and D.T. Hopkins, Eds.) Am. Assoc. of cereal chemist. St. Paul, Minnesota, pp: 31-46.

Asuquo, B.O. and B. Okon, 1993. Effects of age and egg size on fertility and hatchability of chicken eggs. E. Air. Agr. For. J., 59: 79-83.

Ayidin, R. and M.E. Cook, 2004. The effects of dietary conjugated linoleic acid on egg yolk fatty acids and hatchability in Japanese quail. Poult Sci., 83: 2016-2022.

Ayidin, R., M.W Pariza and M.E. Cook, 2001. Olive oil prevents the adverse effects of dietary conjugated linolieic acid on chick hatchability and egg quality. J. Nutr., 131:800-806. 
Ayo, J.O., J.A. Obidi and P.l. Rekwot, 2010. Seasonal variation in feed consumption, hen-day, mortality and culls of Bevans Black chickens. Proceedings of the 13th annual conference of the Nigerian society of Animal Production. 14-17th March, pp: 415-418.

Bakst, M.R., 1998. Structure of the avian oviduct with emphasis on sperm storage in poultry. J. Expt. ZooI., 282: 618-626.

Bakst, M.R., G. Mshart and J.P. Brillard, 1994. Oviductal sperm selection, transport and storage in poultry. Poult Sci. Rev., 5: 117-143.

Banks, S., SA King, D.S. Irvine and P.TK Sanders, 2005. Impact of mild scrotal heat stress on DNA integrity in murine spermatozoa. Reproduction, 62: 505-514.

Bauer, F., S.G. Tulle and H.R. Wilson, 1990. Effects of setting eggs small end up on hatchability and post hatching performance of broilers. Br. Poult. Sci., 31: 715-724.

Bender, H.S., GK Sauders and H.P. Misra, 1988. A histopathologic study of the effects of gossypol on the female rat Contraception, 38: 585.

Benette, C.D., 1992. The influence of shell thickness on hatchability in commercial broiler flocks. J. Appl. Poult Res., 1:61-65.

Brah, G.S. and J.S. Sandhu, 1989. Preincubation storage of guinea fowl eggs in cooling cabinet vs. room: Effect on hatchability components. Trop. Agric. (Trinidad and Tobago), 66: 265-268.

Brammel, RK, C.D. Mcdaniel, J.L. Wilson and B. Howarth, 1996. Age effect of male and female broiler breeders on sperm penetration of periveitelline layer overlying the germinal disc. Poult. Sci., 75: 755-762.

Brillard, J.P., 2003. Practical aspects of fertility in poultry. World's Poult Sci. J., 59: 441-446.

Brillard, J.P., 2007. Control of fertility in turkeys: the impact of environment, nutrition and artificial insemination technology. Poultry Industry Technical articles.

Brommer, J.E. and K. Rattiste, 2008. Hidden reproductive conflict between mates in a wild bird population. Evolution, 62: 2326-2333.

Brotherstone, S., I.M.S. White and K. Meyer, 2000. Genetic modeling of daily milk yield using orthogonal polynomials and parametric curves. Anim. Sci., 70: 407-415.

Buhr, R.J., 1995. Incubation relative humidity effects on allantoic fluid volume and hatchability. Poult Sci., 74: 874-884.

Cantor, A.H. and M.L. Scott, 1974. The effect of selenium in the hen's diet on egg production, hatchability and performance of progeny and selenium concentration in eggs. Poult. Sci., 53: 1870-1880.

Chabassi, C.S., S. Taddei, G. Predari, G. Galvani, F. Ghidini, E. Schiano and S. Cavirani, 2004. Bacteriologic finding in ostrich (Struthio came/us) eggs from farms with reproductive failure. Avian Dis., 48: 716-722.

Chamruspollert, M. and J.L. Sell, 1999. Transfer of dietary conjugated linoleic acid to egg yolk of chickens. Poult Sci., 78: 1138-1150.

Chattock, A.P., 1925. On the physics of incubation. Phil. Trans. B., 213: 397-450.

Davtyan, D., T. Papazyan and L. Nolle!, 2006. Dose response of Se added as sodiumselenite or Sei Piex on sperm quality and breeder productivity. XII European Poultry Conference, Verona, Italy, 1015 September.

Deeming, D.C. and J.H. Middelkoop, 1999. Effect of strain and flock age on fertility and early embryonic mortality of broiler breeder eggs. $\mathrm{Br}$. Poult Sci., 40: 522-526.

Deeming, D.C., 1995. Factors affecting hatchability during commercial incubation of ostrich (Struthio came/us) eggs. Br. Poult Sci., 36: 51-65.

Dikmen, B.Y. and U. Sahan, 2007. Correlations between breeder age, egg cholesterol content, blood cholesterol level and hatchability of broiler breeders. Br. Poult Sci., 48: 98-103.

Donaldson, WE. and B.L. Files, 1970. Embryo mortality in quail induced by cyclopropene fatty acids; reduction by maternal diets high in unsaturated fatty acids. J. Nutr., 100: 605-610.

Edens, F.W., 1983. Effects of environmental stressors on male reproduction. Poult Sci., 62: 1676-1689.

Elibol, 0. and J. Brake, 2003. Effect of frequency of turning from three to eleven days of incubation on hatchability of broiler hatching eggs. Poult Sci., 82: 357-359.

Fasenko, G.M., J.L. Mison, F.E. Robinson and R.T. Hardin, 1999. Effects of egg nest holding time and high environmental temperature on prestorage embryonic development, survival and hatchability of broiler breeders. J. Appl. Poult Res., 8: 488-492.

Folie!, BK and J.E. Robinson, 1980. Photoperiod and gonadotrophin secretion in birds. Prog. Reprod. Bioi., 5: 39-61.

Harms, R.H., B.L. Damron and P.W Waldrop, 1966. Influence of strain or breed upon the protein requirement of laying hens. Poult Sci., 45: 272275.

Hassan, S.M., A.A. Siam, M.F. Mady and A.L. Cartwright, 2004. Incubation temperature for ostrich (Struthio came/us) eggs. Poult Sci., 83: 495.

Islam, M.S., MAR. Howlinder, F. Kabir and J. Alam, 2002. Comparative assessment of fertility and hatchability Barred Plymouth Rock, White Leghorn, Rhode Island Red and White Rock Hen. Int. J. Poult Sci., 1: 85-90.

Javanka, L., 0. Djuragic and S. Sredanovic, 2010. Use of feed from brewery by-products for breeding layers. Romanian Biotech. Lett., 15: 5559-5565. 
King'ori, A.M., J.K. Tuitoek, H.K. Muiruri and A.M. Wachira, 2010. Effect of dietary protein levels on egg production, hatchability and posthatch offspring performance of indigenous chickens of Kenya. Int. J. Poult Sci., 9: 324-329.
Mothershaw, A.S.; Gaffer, T.; Kadim, I.; Guizani, N.; Al-Amri, I.; Mahgoub, O. and Al-Bahry, S. (2009). Quality characteristics of broiler chicken meat on salt at different temperatures. Int. J. Food Prop. 12: 681-690.

تأثير المعاملة الحرارية لبيض التفريخ لفترة قصيرة خلال فترة التخزين , فترة التخزين وعمر القطيع علي إنتاجي بداري

$$
\text { التسمين }
$$

محمد سويلم حسن, احمد ابو السعود رضوان, جعفر محمود الجندي, أسامة حسن منصور الجارحي

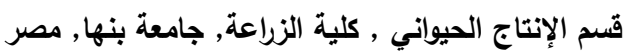

هذفت هذه الدراسة الى البحث في تطبيق المعاملة الحرارية لبيض التفريخ لفترة قصيرة خلال قترة التخزين وعلاقته بقترة التخزين وعمر

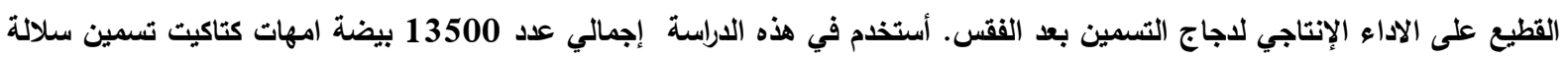
(روص- 308)- - تم الحصول عليها من شركة الدقهلية للاواجن- وتم تفريخها في مؤسسة التنمية للتفريخ والانتاج الداجنى , الخانكة-

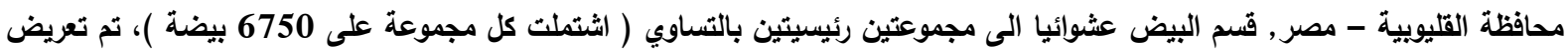
بيض المجموعة الاولى الى درجة حرارة خلال فترة التخزين الى 105 درجة فهرنهيت لمدة 3.5 ساعة (لتصل درجة حرارة قثشرة البيضة الى 100

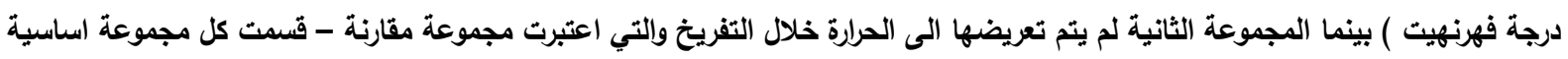
الى ثلاث تحت مجموعات رئيسية ( تثمل كل منها على 2250 بيضة) تبعا الى عمر القطيع (29 , 42 , 58 اسبوع على التوالي) - وقسمت كل تحت مجموعة تبعا لفترة التخزين الى ثلاث مجموعات ( 6, 10 , 14 يوم على التوالي ). تتلخص النتائج المتحصل عليها الى ان الكتاكيت

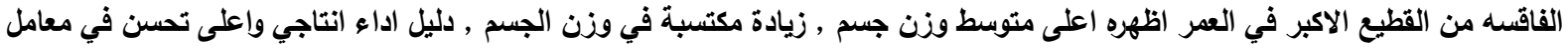

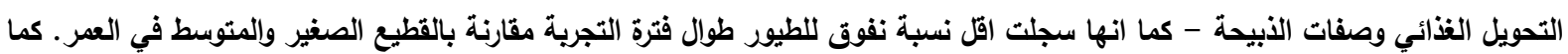

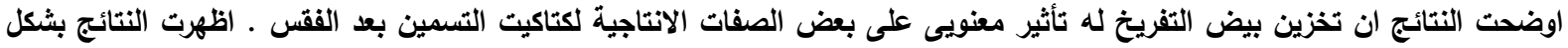

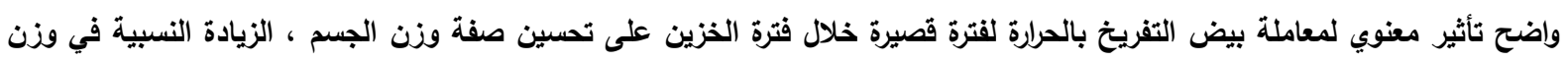

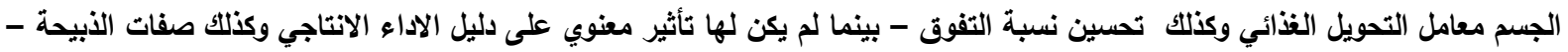

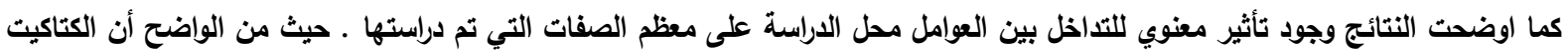

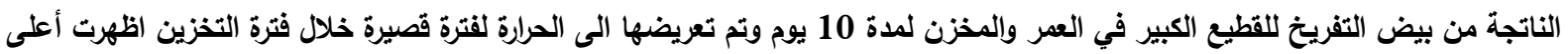

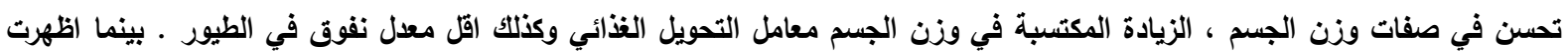
الكتاكيت الفاقسه من البيض الناتج من القطيع الكبير في العمر والمخزن لمدة 6 ساعة وتم رفع درجة حرارته خلال فترة التفريخ زيادة معنوية

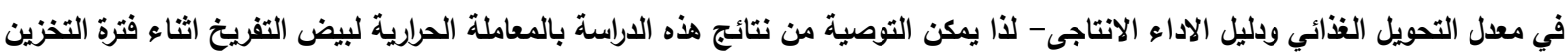
لتحسين الاداء الانتاجي للكتاكيت الفاقسة - كنلك اوضحت الدراسة ان الكتاكيت الفاقسة من بيض القطيع الكبير في العمر والمخزن لمدة 10 ايام وتم معاملته بالحرارة افضل النتائج في تحسين انتاجية كتاكيت التسمين. 